\title{
nature
}

\section{Collaborations essential for food in the developing world}

The stakes in the debate on genetically modified crops increase dramatically as it moves to the developing countries. Governments need to help existing agencies to rise to the challenges.

$\mathrm{T}$ o stand idly by while 40,000 children a day are dying from diseases related to malnutrition would, as was rightly pointed out at a meeting on agricultural biotechnology in Washington last week, be scandalous behaviour. But to agree with that sentiment is not to infer that the immediate, large-scale commercialization of transgenic crops is necessarily in the best interests of the world's poor.

The meeting, which was organized by the influential Consultative Group on International Agricultural Research (CGIAR), was called "Ensuring food security, protecting the environment, reducing poverty in developing countries: Can biotechnology help?", and the answer to the question is obviously 'yes' (see page 831). Transgenic technology clearly has the potential, for example, to enhance the nutritional value of rice in ways that might help balance the diets of hundreds of millions of people who depend on the crop.

But there are many approaches that plant scientists can take to improve subsistence crops, and that politicians can take to strengthen subsistence agriculture, which do not require transgenic technology. The earliest manifestations of the technology — crops that produce their own insecticides or resist expensive weed-killers - have little relevance to farmers in most of the developing world. The immediate priority for these countries is to obtain the best possible information about this rapidly evolving field, so that their governments can make informed choices endorsed by public support. That is where guidance from organizations such as CGIAR will be essential. The group, which coordinates the activities of 16 major food-research laboratories in developing countries, has the credibility needed to help Third World countries make adequately informed decisions.

These laboratories led the first Green Revolution, which transformed subsistence agriculture by giving poor farmers access to better seed and basic technology, and doubled the global cereal crop between 1960 and 1990. But that revolution was pioneered by plant scientists working in publicly funded laboratories. The next transformation of agriculture is being driven by industrial corporations. It is difficult to see how the interests of poor farmers will necessarily be protected during this transformation, particularly as most of the research and development currently under way is aimed at intensive commodity farming, primarily in the industrialized world. Furthermore, whereas the Green Revolution was based on freely available breeding techniques, transgenics technology involves a spider's web of patent-protected information.

Unless the corporations holding most of that information can win the trust of the developing countries, their revolution will fail. Some business leaders, to their credit, have been calling for a stronger public-sector research effort in agricultural biotechnology, and philanthropic organizations such as the Rockefeller Foundation are providing important support. But, given the lack of available public resources, it may fall to the corporations to help pay for such an effort.

Nevertheless, governments in the industrialized world must acknowledge that organizations such as CGIAR can help developing countries to manage transgenic technology, and resource these groups accordingly. The standard policy at the moment (best exemplified by the United States) is to curtail foreign aid, warning that it creates 'dependency', while lavishing vast subsidies on domestic farmers, who in turn crush the more advanced commodity farmers of the developing world beneath a mountain of subsidized grain.

Governments in the developing world face an immense challenge in deciding what to do with the new technology. They can start by avoiding the mistake the industrialized world made by commercializing genetically modified crops without a genuine attempt at first winning public trust. They will need to work more closely together than they have in the past, through CGIAR and other forums. Ultimately, they may take the lead in applying a technology that, despite its early false steps, should play a significant part in alleviating world hunger.

\section{Code for fairer lab management}

A debate on the prospects for women in science reveals some pessimism as well as constructive ideas of wider relevance.

S exual discrimination was a precursor of the spy scandal at Los Alamos (Cheryl Fillekes). Children are more interesting than fleas (Miriam Rothschild). These are among the most striking statements that emerged during Nature's six-week online discussion of the problems facing women in science, which ended last week (see http://helix.nature.com/debates/women). (To do her justice, Rothschild was making the more serious point that significant science can be done at home.)

But there was much else besides: how being a mother can lead to enhanced research productivity; the policy of telecommunications giant Ericsson of encouraging men to spend time at home with their children on the principle that this makes them better managers; a woman in a pharmaceutical company describing the "grooming of the male establishment-in-waiting", thanks to chauvinism and cronyism; and disagreement about men being recruited to promote women's interests. Amid complaints that men are unwilling to share family burdens, there were examples of constructive initiatives within particular institutions and at a national level in several countries.

One productive way forward (Samuel Gorovitz) would be to build on codes of practice such as the National Academy of Sciences' "On being a scientist". A better code would also cover a range of issues that arise in laboratories and universities - including hierarchy, mentoring and the freedom to question, as well as sexual discrimination. Such a code, effectively backed, might leave no hiding place for those who discriminate unjustly. It should be high on the agenda of any laboratory that lacks it. 